\title{
The Necrotic Pathotype of the Cucumber mosaic virus (CMV) Ns Strain Is Solely Determined by Amino Acid 461 of the 1a Protein
}

\author{
Zoltán Divéki, Katalin Salánki, and Ervin Balázs \\ Agricultural Biotechnology Center, Environmental Biosafety Research Institute, P.O. Box 411. Gödöllö, H-2101 Hungary
}

Submitted 18 February 2004. Accepted 29 April 2004.

\begin{abstract}
The unique Ns isolate of Cucumber mosaic virus (CMV) induces necrotic lesions on several Nicotiana spp. in contrast to other strains that cause systemic mosaic on these plants. By using biologically active RNA transcripts from cDNAs of Ns-CMV and a reference subgroup I strain Rs-CMV, we confined the genetic determinant solely responsible for necrosis induction to amino acid 461 of the 1a protein translated from genomic RNA1. An Arg to Cys change at this position ( $R 461 C$ ) rendered Rs-CMV necrotic, whereas the reciprocal $\mathrm{C461R}$ mutation reverted the necrotic phenotype of Ns-CMV. Necrotic (Ns-CMV, R461C) and non-necrotic (Rs-CMV and C461R) viruses accumulated to similar levels in Nicotiana clevelandii protoplasts. Deletion of the residue at position 461 abolished replicase activity of the Ns-CMV 1a protein. The $\mathrm{R461C}$ mutation also was introduced into the 1a protein of Trk7-CMV, a subgroup II isolate. Symptoms induced by the Trk7/R461C mutant were identical to those caused by wild-type Trk7-CMV, even when the mutant Trk7 RNA1 was co-inoculated with RNA2 and 3 of the necrotic Ns strain.
\end{abstract}

Additional keywords: hypersensitive response.

Symptom appearance during the course of viral infection is a result of a complex interaction between the virus and the host plant. However, host plants have evolved effective strategies to minimize the damaging effect of the infection. One such protection mechanism is the hypersensitive response (HR), elicited by a broad spectrum of pathogens, including viruses (Goldbach et al. 2003). An HR is characterized by the confinement of the infection through programmed cell death, which prevents further spread of the pathogen (Heath 2000). One of the characteristic symptoms associated with the HR is the appearance of necrotic local lesions, visible signs of mass cell necrosis. HR is considered to be a result of a receptorligand interaction between a host resistance gene product and a corresponding pathogen-encoded avirulence factor (Hutcheson 1998). Indeed, the gene-for-gene concept is supported by experimental evidence; moreover, many avirulence factors and several resistance genes have been identified (Hulbert et al. 2001; Hutcheson 1998).

\section{Corresponding author: Ervin Balázs; E-mail: balazs@abc.hu}

Current address of Z. Divéki: Ris $\emptyset$ National Laboratory, Plant Research Department; P.O. Box 49. Roskilde, DK-4000 Denmark.

The nucleotide sequences reported in this paper are available from the EMBL database under the accession numbers AJ580953, AJ511989, AJ511990, AJ511988, AJ517801, and AJ517802.
The small icosahedral Cucumber mosaic virus (CMV) is the type member of the genus Cucumovirus in the family Bromoviridae. CMV has an unusually broad host range, encompassing over 1,000 species (Palukaitis et al. 1992). Based on serological and sequence data, CMV strains have been categorized into three subgroups, IA, IB, and II (Roossinck et al. 1999). The tripartite CMV genome consists of single-stranded positive sense RNAs. RNA1 and RNA2 code for the 1a and 2a proteins, respectively, which are the core elements of the replicase complex (Hayes and Buck 1990). Two functional domains can be distinguished in the 1a protein: the $\mathrm{N}$-terminal region shows sequence homology to methyltransferases while the $\mathrm{C}$-terminal region contains motifs characteristic of viral and cellular helicases (Gorbalenya et al. 1988; Haseloff et al. 1984). The conserved GDD motif, characteristic of RNA polymerases, is present in the $2 \mathrm{a}$ protein, the other viral component of the replicase complex (Habili and Symons 1989). RNA3 codes for two proteins, $3 \mathrm{a}$ and the coat protein $(\mathrm{CP})$; the latter is translated from a subgenomic RNA (RNA4). Both RNA3 gene products are essential for the short-distance movement of CMV (Canto et al. 1997). The smallest CMV protein, $2 \mathrm{~b}$, is translated from the subgenomic RNA4A of RNA2 with a partially overlapping open reading frame to the $3^{\prime}$ end of the $2 \mathrm{a}$ gene. The $2 \mathrm{~b}$ protein is a host range determinant (Ding et al. 1995) and a suppressor of posttranscriptional gene silencing (Brigneti et al. 1998). Nonlethal mutations in any of the five genes of CMV can alter symptomatology, host range, or both (Kim and Palukaitis 1997; Li et al. 2001; Roossinck and Palukaitis 1990; Shi et al. 2002; Szilassy et al. 1999a). CP and 2a also have been identified as possible HR avirulence factors in tobacco and cowpea, respectively (Kim and Palukaitis 1997; Takahashi et al. 2000).

Although most CMV strains systemically infect Nicotiana spp., there are two known exceptions that induce necrotic lesions. First, CMV(Y/GM2), a derivative of the yellow CMV strain (Y-CMV), triggers an HR on nine Nicotiana spp. (Takahashi et al. 2000). The other necrotic strain is N-CMV, which was isolated and described as a chance mutant by Fulton (1953). In addition to $N$. benthamiana and $N$. clevelandii, which are susceptible both locally and systemically, $\mathrm{N}-\mathrm{CMV}$ induces only necrotic local lesions on a wide range of $N$. tabacum cultivars as well as on other solanaceous species (e.g., Atropa, Capsicum, Datura, Nicotiana, and Physalis spp.) (Fulton 1953; Salamon et al. 1998). N. glutinosa previously has been thought to be resistant to the virus; however, the stock culture of N-CMV occasionally induced necrotic local lesions on these plants. From the lesions, a derivative of the $\mathrm{N}$ strain, Ns-CMV, was isolated. Apart from regularly inducing necrotic local lesions and very rarely systemic mosaic (especially after longer incubation) on N. gluti- 
nosa, the pathological properties of the derivative strain are identical to those of N-CMV (Salamon et al. 1998). Based on double-gel immunodiffusion tests and on the nucleotide sequence of the RNA3, N-CMV was classified as a subgroup I isolate (Salamon et al. 1998).

Although it has been shown that the unusual symptoms of the N-CMV can be linked to genomic RNA1 (Lakshman and Gonsalves 1985), the exact localization and nature of the genetic determinant responsible for lesion induction remained unknown.

In order to map the necrotic determinant, we used Rs-CMV as a reference strain. Rs-CMV was isolated from Raphanus sati$v u s$ and belongs to subgroup I, causing green systemic mosaic on all Nicotiana hosts (P. Salamon, unpublished data). By using Ns-CMV/Rs-CMV reassortant, chimeric, and point mutant viruses, one amino acid in the viral 1a protein was identified as the necrotic determinant of Ns-CMV. In the present work, we also have examined whether this single amino acid change is able to induce necrosis in a different genetic context.

\section{RESULTS}

Symptomatology and test of the full-length cDNA clones. Although both Ns-CMV and Rs-CMV belong to subgroup I, the symptoms of infection were strikingly different. Whereas the Rs strain caused the typical systemic mosaic characteristic of CMV infection on all tested Nicotiana plants (N. clevelandii, N. glutinosa, and N. tabacum cv. Xanthi-nc) with no local symptoms (Table 1; Fig. 1, left panel), the Ns strain induced necrotic local lesions 4 days postinoculation (dpi) on these species (Table 1; Fig. 1, right panel). The Ns-CMV infection became systemic only in $N$. clevelandii plants, where the virus caused progressive necrosis of systemically infected leaves, leading to the collapse of the plant $21 \mathrm{dpi}$ (Table 1). There was also a difference in the time required for the appearance of the systemic symptoms between Ns- and Rs-CMV. The first signs of systemic necrosis were observed 5 to 6 dpi on $N$. clevelandii infected by NsCMV, whereas Rs-CMV induced systemic mosaic only 7 to 9 dpi on all Nicotiana spp.

Full-length cDNA clones were synthesized from both Ns and Rs viral genomes for further investigations. In order to verify the sequence integrity of the cDNA clones of the two strains, test plants were co-inoculated with capped in vitro RNA transcripts of the pN1, pN2, and $\mathrm{pN} 3$, and $\mathrm{pR} 1, \mathrm{pR} 2$, and $\mathrm{pR} 3$ clones, respectively. Both genomic clone sets were infectious and the induced symptoms were identical to the original viruses (i.e., Ns-CMV and Rs-CMV) (Table 1). Nucleotide sequence of the genomic clones have been determined and submitted to the EMBL database under accession numbers AJ580953, AJ511989, AJ511990, AJ511988, AJ517801, and AJ517802. Analysis of the sequence data has confirmed the earlier serology-based classification of the strains to subgroup I.

Table 1. Symptoms of the wild-type, reassortant, chimeric, and point mutant viruses 10 days postinoculation

\begin{tabular}{|c|c|c|c|}
\hline \multirow[b]{2}{*}{ Genotype } & \multicolumn{3}{|c|}{ Infection phenotype $^{a}$} \\
\hline & Nicotiana clevelandii & N. glutinosa & N. tabacum cv. Xanthi-nc \\
\hline \multicolumn{4}{|l|}{ Wild type viruses } \\
\hline $\mathrm{R} 1 / \mathrm{R} 2 / \mathrm{R} 3$ & 1 & 2 & 3 \\
\hline $\mathrm{N} 1 / \mathrm{N} 2 / \mathrm{N} 3$ & 5 & 6 & 7 \\
\hline Trk1/Trk2/Trk3 & 9 & 4 & 4 \\
\hline \multicolumn{4}{|c|}{ Ns-CMV/Rs-CMV reassortants ${ }^{\mathrm{b}}$} \\
\hline $\mathrm{R} 1 / \mathrm{R} 2 / \mathrm{N} 3$ & 1 & 2 & 3 \\
\hline $\mathrm{R} 1 / \mathrm{N} 2 / \mathrm{R} 3$ & 1 & 2 & 3 \\
\hline $\mathrm{R} 1 / \mathrm{N} 2 / \mathrm{N} 3$ & 1 & 2 & 3 \\
\hline $\mathrm{N} 1 / \mathrm{N} 2 / \mathrm{R} 3$ & 5 & 6 & 7 \\
\hline $\mathrm{N} 1 / \mathrm{R} 2 / \mathrm{N} 3$ & 5 & 6 & 7 \\
\hline $\mathrm{N} 1 / \mathrm{R} 2 / \mathrm{R} 3$ & 5 & 6 & 7 \\
\hline \multicolumn{4}{|l|}{ RNA1 chimeras } \\
\hline NR/R2/R3 & 5 & 7 & 7 \\
\hline $\mathrm{RN} / \mathrm{R} 2 / \mathrm{R} 3$ & 1 & 2 & 3 \\
\hline N.RNR/R2/R3 & 5 & 7 & 7 \\
\hline R.NRN/R2/R3 & 1 & 2 & 3 \\
\hline RNR-Bsm/R2/R3 & 5 & 7 & 7 \\
\hline NRN-Bsm/R2/R3 & 1 & 2 & 3 \\
\hline RNR-Csp/R2/R3 & 5 & 7 & 7 \\
\hline NRN-Csp/R2/R3 & 1 & 2 & 3 \\
\hline NRN-Csp/N2/N3 & 1 & 2 & 3 \\
\hline \multicolumn{4}{|c|}{ 1a protein point mutants } \\
\hline $\mathrm{rL} 456 \mathrm{~F} / \mathrm{R} 2 / \mathrm{R} 3$ & 1 & NA & NA \\
\hline $\mathrm{rR} 461 \mathrm{C} / \mathrm{R} 2 / \mathrm{R} 3$ & 5 & 7 & 7 \\
\hline $\mathrm{rV} 462 \mathrm{Q} / \mathrm{R} 2 / \mathrm{R} 3$ & 1 & NA & NA \\
\hline $\mathrm{rV} 467 \mathrm{~A} / \mathrm{R} 2 / \mathrm{R} 3$ & 1 & NA & NA \\
\hline $\mathrm{rH} 469 \mathrm{R} / \mathrm{R} 2 / \mathrm{R} 3$ & 1 & NA & NA \\
\hline $\mathrm{nC} 461 \mathrm{R} / \mathrm{N} 2 / \mathrm{N} 3$ & 1 & 2 & 3 \\
\hline $\mathrm{n} \Delta 461 / \mathrm{N} 2 / \mathrm{N} 3$ & 0 & 0 & 0 \\
\hline tR461C/Trk2/Trk3 & 9 & 4 & 4 \\
\hline \multicolumn{4}{|c|}{ Intersubgroup reassortants } \\
\hline $\mathrm{N} 1 /$ Trk2/Trk3 & 8 & 7 & 7 \\
\hline rR461C/Trk2/Trk3 & 8 & 7 & 7 \\
\hline tR461C/R2/R3 & 1 & 2 & 2 \\
\hline $\mathrm{tR} 461 \mathrm{C} / \mathrm{N} 2 / \mathrm{N} 3$ & 1 & 2 & 2 \\
\hline
\end{tabular}

${ }^{a}$ Infection phenotype codes; slash (/) separates local and systemic symptoms, and rarely or slowly appearing symptoms are in parentheses: $0=$ asymptomatic; 1 = none/leaf deformation, green mosaic; $2=$ none/green mosaic; $3=$ none/green mosaic, vein clearing; $4=$ none $/$ mild green mosaic; $5=$ necrotic lesions/necrotic lesions (apical necrosis); $6=$ necrotic local lesions/none (green mosaic); $7=$ necrotic local lesions/none; $8=$ necrotic lesions/necrotic lesions, apical necrosis; $9=$ chlorotic spots/leaf deformation; NA = not assayed.

${ }^{\mathrm{b}} \mathrm{CMV}=$ Cucumber mosaic virus . 


\section{Confinement of the necrosis-inducing sequence} to a 175-nucleotide section of RNA1.

In order to identify which genomic RNA molecule or molecules were responsible for necrosis induction, all six possible reassortant viruses were prepared by combining the transcripts of the Rs-CMV and Ns-CMV cDNA clones. Nicotiana test plants were co-inoculated with the reassorted RNA transcripts. Symptoms caused by viruses carrying the RNA1 molecule of the Rs strain were similar to those induced by
Rs-CMV (Table 1). In contrast, reassortants bearing RNA1 of the Ns strain induced necrotic local lesions at 4 dpi that were indistinguishable from those caused by Ns-CMV (Table 1). These results confirmed that necrosis induction is determined solely by the RNA1 molecule in the reassorted genome (Lakshman and Gonsalves 1985). We did not find significant influence of the origin of RNA2 and RNA3 molecules either on the appearance of symptoms or on the kinetics of the infection.

\section{Rs-CMV}

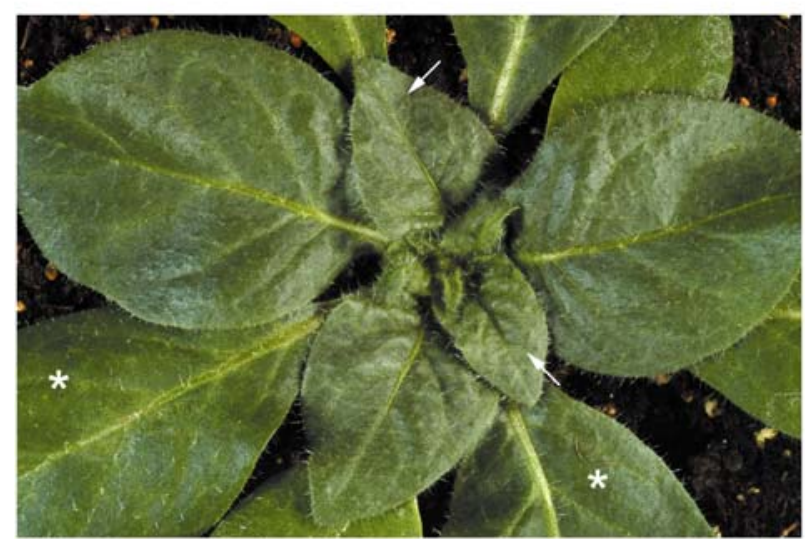

\section{Ns-CMV}

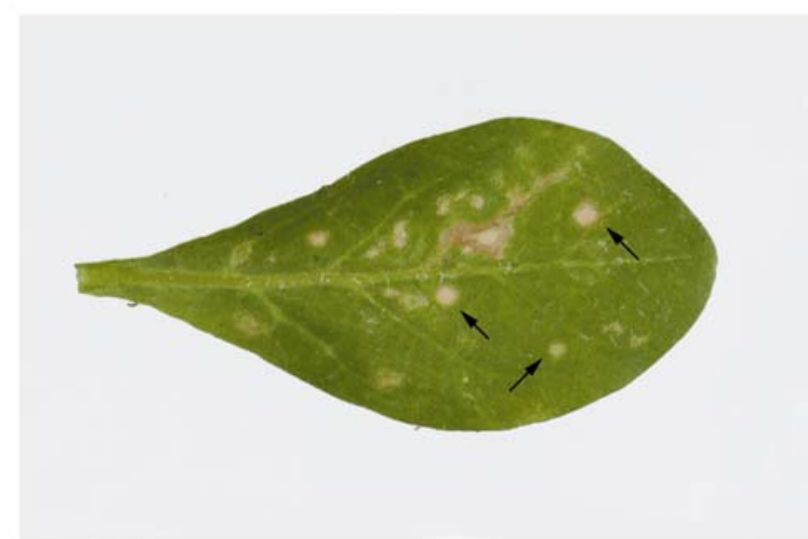

Nicotiana clevelandii
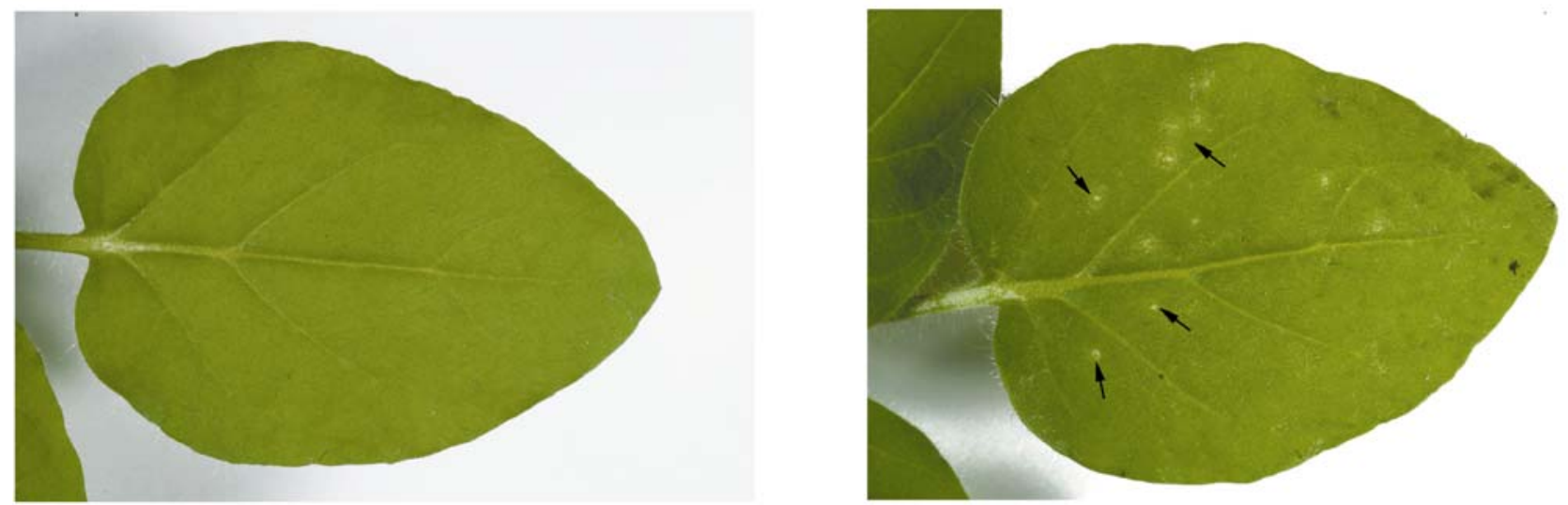

\section{Nicotiana glutinosa}
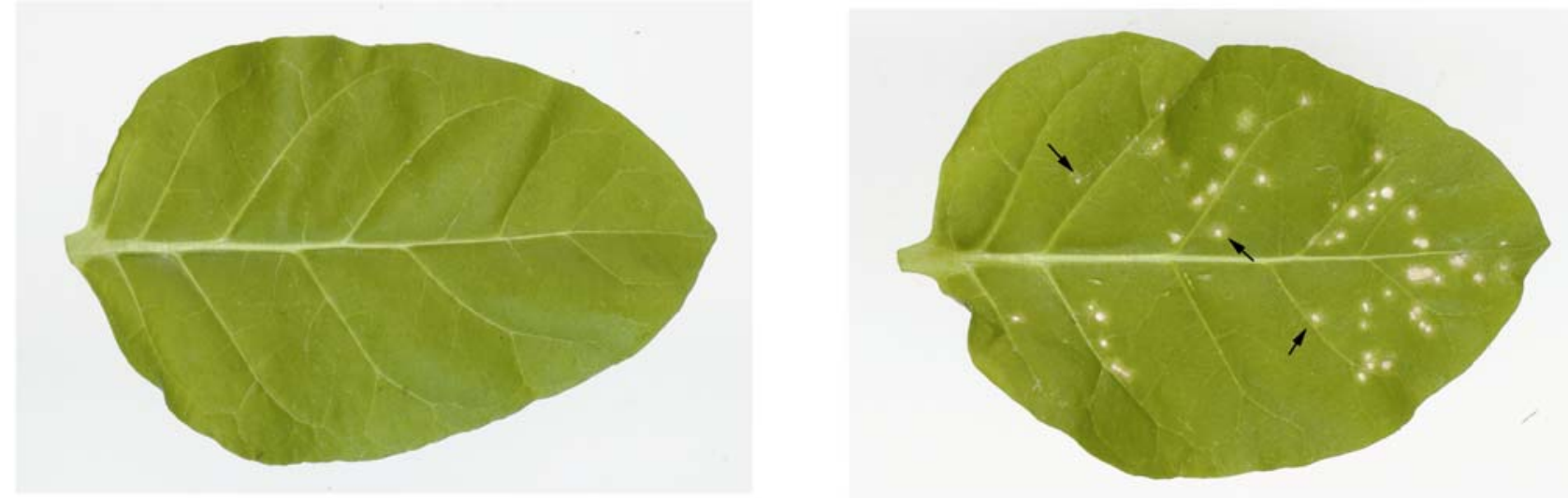

Nicotiana tabacum cv. Xanthi-nc

Fig. 1. Local symptoms induced by Rs-Cucumber mosaic virus (CMV) and Ns-CMV 10 days postinoculation on Nicotiana clevelandii (top), N. glutinosa (middle), and N. tabacum cv. Xanthi-nc (bottom). Black arrowheads indicate necrotic local lesions. On Rs-CMV-infected N. clevelandii, white arrowheads indicate systemic symptoms; inoculated leafs are marked with asterisks. Inoculations were performed with purified virions at $10 \mu \mathrm{g} / \mathrm{ml}$. 
By using common restriction endonuclease sites in the $\mathrm{pN} 1$ and $\mathrm{pR} 1$ clones, a series of reciprocal cDNA1 chimeras was created to further confine the sequence responsible for the necrotic pathotype (Fig. 2A). Transcripts from the chimeric
cDNA1 molecules were combined with transcripts from the $\mathrm{pR} 2$ and $\mathrm{pR} 3$ clones prior to the inoculation of different Nicotiana plants. The symptoms induced by the chimeric viruses are summarized in Table 1. pNR and pRN chimeras localized

\section{A}

R1

\begin{tabular}{|l|rr||r|r|} 
ApaI & Bsm & Csp45I \\
Bsmi & Eco RV Bam HI \\
\hline & & & & \\
\hline
\end{tabular}

N1

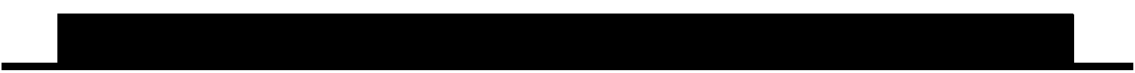

NR



RN

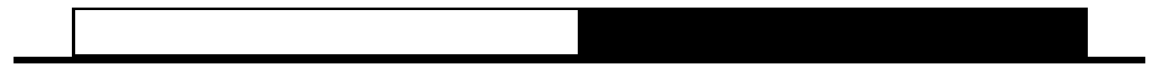

N.RNR

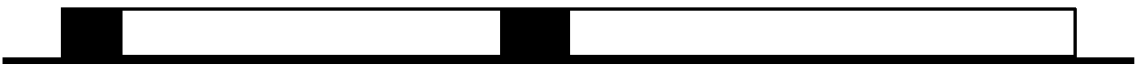

R.NRN

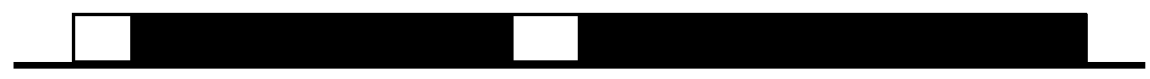

RNR/Bsm

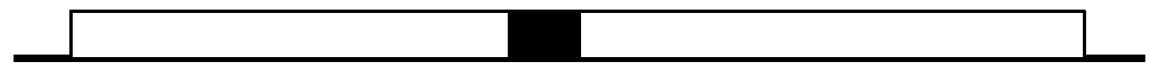

NRN/Bsm

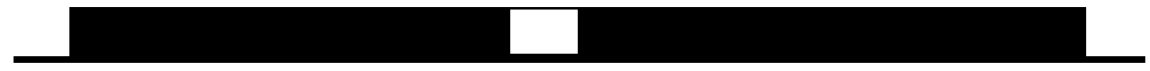

$\mathrm{RNR} / \mathrm{Csp}$



$\mathrm{NRN} / \mathrm{Csp}$

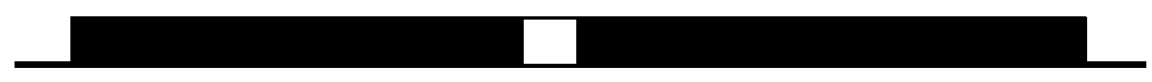

B

\section{Strain name}

CMV-RS
CMV-Ns
CMV-Trk 7
TAV-V
PSV-J

450 SKWFAALTRPLRVFFSSVVHALFPTLR

$450 \ldots . . . . . . C Q \ldots$. . . . . . .

450 W...SMS....... T.KT....

449 R.F..S....M...I.AC.KT.....

445 .Q.WK.M.K.I.T.VRL.A.T. . . .
EMBL accession number

AJ580953

AJ511988

AJ007933

NC 003837

D11126

Fig. 2. A, Chimeric Cucumber mosaic virus (CMV) cDNA1 molecules. Black and white bars indicate the Ns-CMV and Rs-CMV origin of the 1a coding segments, respectively. Restriction endonuclease sites common to $\mathrm{pN} 1$ and $\mathrm{pR} 1$ were used for the construction of the chimeras. In vitro transcripts of the chimeric cDNA1s were co-inoculated with transcripts from the $\mathrm{pR} 2$ and $\mathrm{pR} 3$ clones. B, Alignment of translated cucumovirus 1a protein sequences corresponding to the $C s p 45$ I to EcoRV section of CMV cDNA1. Two subgroup I CMV (Rs and Ns), a subgroup II CMV (Trk7), as well as sequences from Tomato aspermy virus (V-TAV) and Peanut stunt virus (3-PSV) were used for the alignment. 
the necrotic lesion inducing genetic determinant to the first 1,616 nucleotides (nt) of the RNA1 molecule. Dissection of the $5^{\prime}$ half of the cDNA1 by pN.RNR and pR.NRN constructs excluded the influence of the BsmI to BsmI (nucleotides 692 to 1,427 ) section on symptom determination. pRNR-Bsm and pNRN-Bsm chimeras demonstrated that sequences upstream of the first BsmI site (nucleotides 1 to 692) also have no effect on lesion induction. The close proximity of a $C s p 45 \mathrm{I}$ site (nucleotide 1,442) to the second BsmI site allowed further confinement of the necrotic determinant to the 175-nt section between the Csp45I and EcoRV restriction enzyme recognition sites. The origin of these $175 \mathrm{nt}$ apparently determines the infection phenotype: even if the RNA transcript of the pNRN-Csp was coinoculated with transcripts from the $\mathrm{pN} 2$ and $\mathrm{pN} 3$ clones, the emerging symptoms were characteristic of Rs-CMV (Table 1).

\section{The crucial role of the amino acid 461 in the 1a protein.}

To our knowledge, there had been only one report describing viral genomic RNA as an elicitor of the HR (Szittya and Burgyán 2001); therefore, we assumed that the necrotic deter-
A

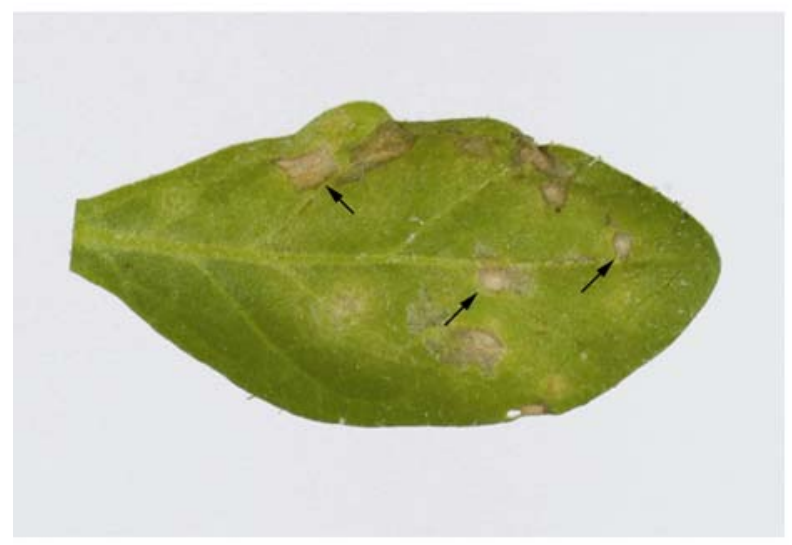

B

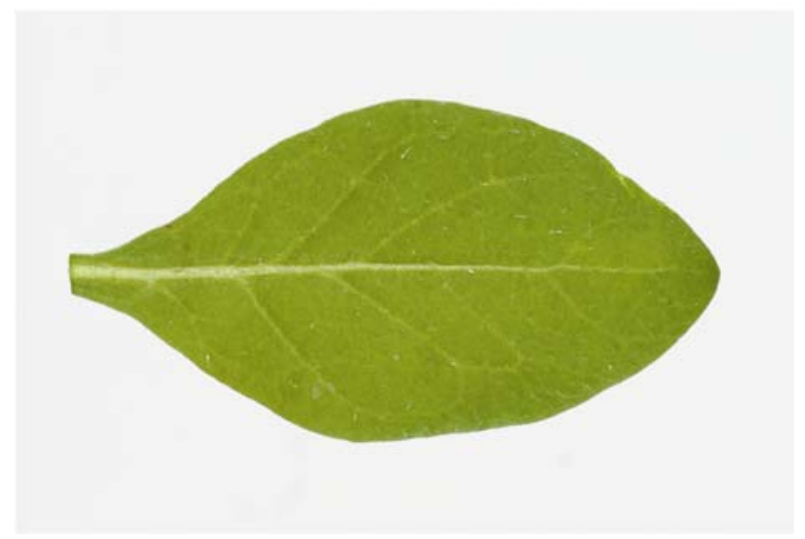

\section{Nicotiana clevelandii}
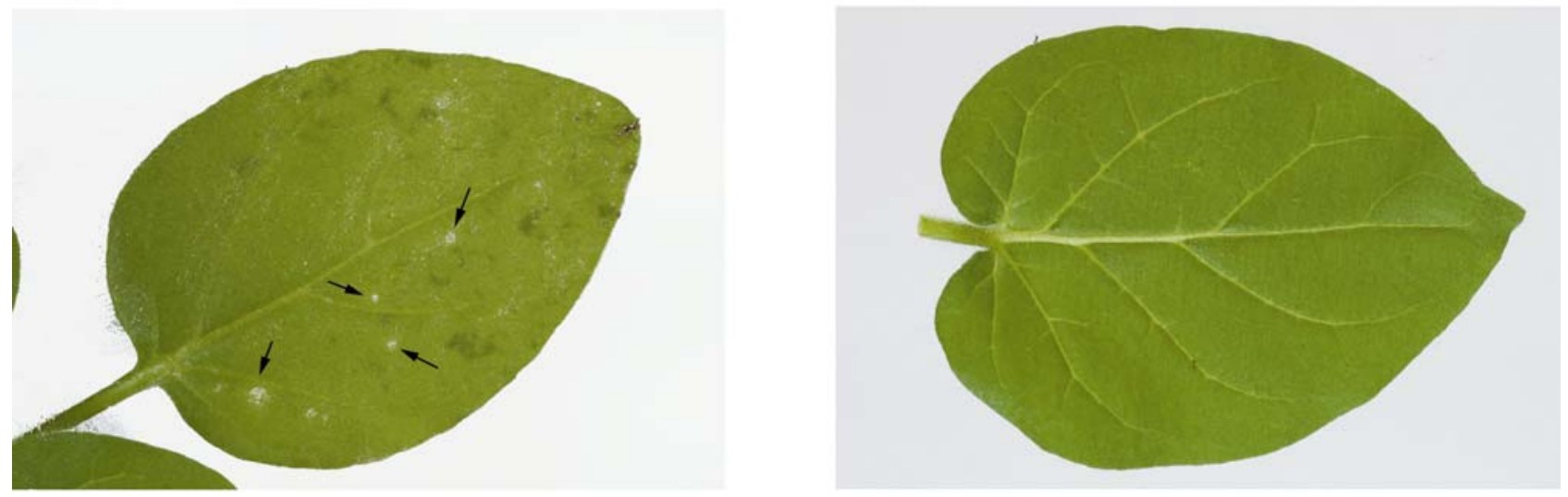

\section{Nicotiana glutinosa}
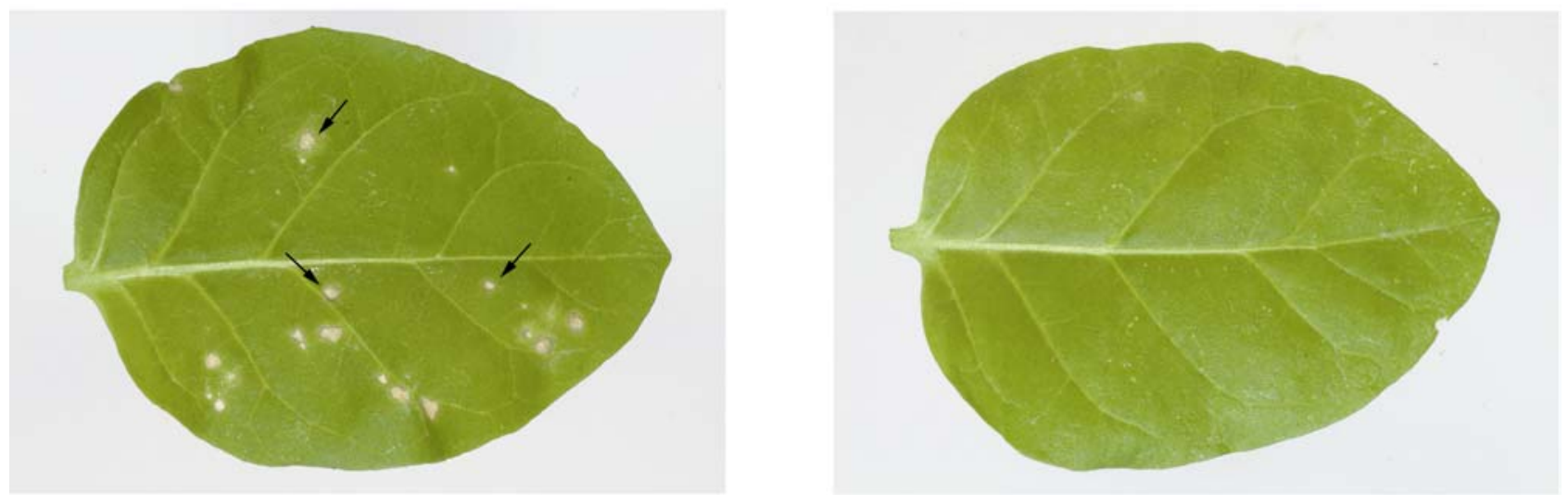

\section{Nicotiana tabacum cv. Xanthi-nc}

Fig. 3. Local symptoms of A, rR461C/R2/R3 and B, nC461R/N2/N3 mutant viruses on Nicotiana plants. Arrowheads indicate necrotic local lesions. Photos were taken 10 days postinoculation. 
minant is expressed at the amino acid level. Comparison of Rs and Ns 1a protein sequences revealed five amino acid differences in the 175-nt cDNA region (Fig. 2B). The occurrence of cysteine at position 461 is unique because, in the genus $\mathrm{Cucu}$ movirus (including Tomato aspermy virus and Peanut stunt virus), all the known 1a proteins contain arginine at this position. In order to identify which amino acid or acids are responsible for the altered infection phenotype of the Ns strain, five pR1-based cDNA1 constructs were designed bearing point mutations in the 1a protein sequence. These mutants were designated as prL456F, prR461C, prV462Q, prV467A, and prH469R, referring to the pR1 origin of the molecule and the sequence change in the encoded 1 a protein. $N$. clevelandii plants were co-inoculated with transcripts from $\mathrm{pR} 2$ and $\mathrm{pR} 3$ and the mutant $\mathrm{pR} 1$ clones. In four cases, the sequence alteration of 1a protein had no effect on the symptoms (Table 1). In contrast, the rR461C mutant induced necrotic lesions 4 dpi on all tested Nicotiana spp. (Table 1). The infection phenotype and the time required for the symptom induction were similar to the Ns-CMV (Fig. 3A). Based on these results, we concluded that amino acid 461 of the 1a protein is a principal determinant of host response in the Ns-CMV/Rs-CMV experimental system. The fact that the predicted secondary structures of the transcribed pR1 and prR461C clones are identical in the Csp45I to EcoRV section (data not shown) supports our preliminary hypothesis that the symptom determinant was expressed at the amino acid level. In order to analyze whether the presence of cysteine at position 461 is solely responsible for lesion induction, pnC461R, a counterpart clone of prR461C, was created based on the $\mathrm{pN} 1$ clone. The test plants that were co-infected with transcripts of pnC461R, pN2, and pN3 showed green systemic mosaic (Table 1) but no local symptoms (Fig. 3B). In general, the symptoms induced by the nC461R mutant were characteristic of Rs-CMV, which confirmed that amino acid position 461 of the 1a protein fundamentally determined the host response given to the infection.

To further analyze the role of amino acid 461 in symptom determination, a deletion mutant of the Ns 1a protein, lacking position $461(\mathrm{n} \Delta 461)$ was constructed. The deletion resulted in a defective virus; no signs of infection were observed on any of the tested Nicotiana plants (Table 1). The absence of infectivity proved to be the result of the impaired replication of $\mathrm{n} \Delta 461$ (discussed below).

We also performed experiments to test whether the change of the canonical arginine in position 461 to cysteine leads to necrotic lesion induction in a virus with different genetic background. The R461C mutation was introduced into the 1a protein of Trk7, a subgroup II CMV strain (Szilassy et al. 1999b), resulting in the clone ptR461C. Test plants co-inoculated with transcripts of ptR461C, pTrk2, and pTrk3 displayed symptoms identical to the wild-type Trk7-CMV: mild systemic mosaic, but no lesions were observed (Table 1). In order to test whether there are subgroup-specific factors located on the RNA2 and 3 molecules contributing to the R461C mutationinduced necrotic response, four intersubgroup reassortants were created. Symptoms of the N1/Trk2/Trk3 and the rR461C/Trk2/Trk3 reassortants indicated that lesion induction was not dependent on the presence of subgroup I RNA2 and 3 (Table 1). Similarly, viruses carrying the mutated Trk7 RNA1 and the RNA2 and 3 molecules of the subgroup I Ns or Rs strains (tR461C/R2/R3 and tR461C/N2/N3) did not induce necrosis on any test plant (Table 1), which shows that it is not the lack of subgroup I-specific factors on RNA2 and 3 that renders the $\mathrm{tR} 461 \mathrm{C} / \mathrm{Trk} 2 / \mathrm{Trk} 3$ virus unable to induce lesions.

\section{Accumulation in protoplasts.}

To determine whether the arginine-cysteine substitution in position 461 of the 1a protein had any influence on the accumulation level of the virus in single cells, protoplasts from fully expanded leaves of $N$. clevelandii were isolated and inoculated with RNAs of the unmodified Ns and Rs strains as well as with RNAs extracted from the rR461C/R2/R3 and $\mathrm{nC} 461 \mathrm{R} / \mathrm{N} 2 / \mathrm{N} 3$ mutant viruses. The radioprobe was synthesized from the $3^{\prime}$ end of the pN3 clone; therefore, the RNA3 and 4 gave a stronger signal than the other two genomic RNAs. At $24 \mathrm{~h}$ after transfection, both the wild-type and mutant viral RNAs accumulated at approximately the same level (Fig. 4A).

Protoplasts transfected by transcripts of pn $\Delta 461, \mathrm{pN} 2$, and $\mathrm{pN} 3$, did not show detectable virus replication (Fig. 4B).
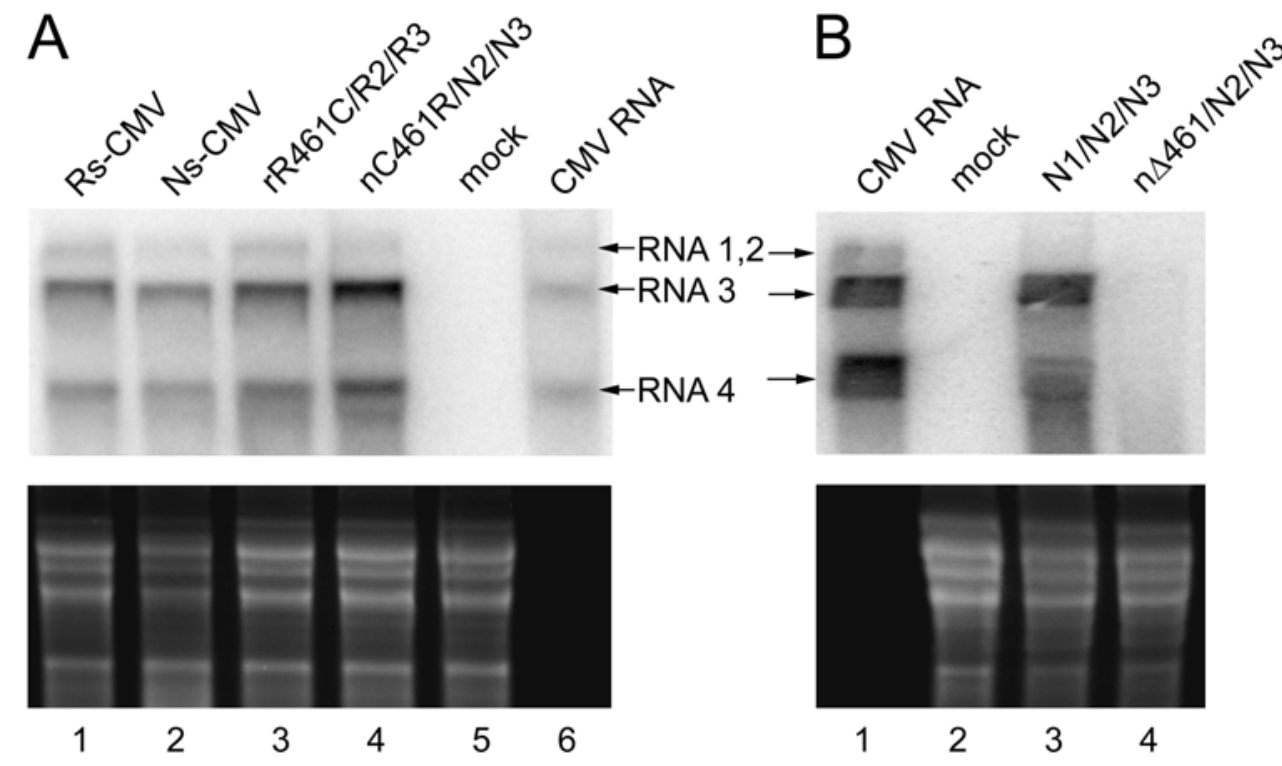
Fig. 4. Accumulation of Cucumber mosaic virus (CMV) RNAs in Nicotiana clevelandii protoplasts $24 \mathrm{~h}$ after transfection. Total nucleic acid extracts from
$2.5 \times 10^{5}$ protoplasts were probed against the radioprobe synthesized from the HindIII to Bam HI fragment (nucleotides 1,563 to 2,216 ) of the pN3 clone. RNA3 and 4 show a stronger signal, although the probe also reacts with RNA1 and 2. A, Protoplasts transfected with $2 \mu \mathrm{g}$ of purified virus RNA. Lane 5, mock inoculated; lane 6, $25 \mathrm{ng}$ of purified Rs-CMV RNA. B, Protoplasts transfected with $2 \mu \mathrm{g}$ of in vitro RNA transcripts. Lane 1, 25 ng of purified RsCMV RNA; lane 2, mock inoculated; lane 3, transfection control. 
These data indicate that, although the arginine-cysteine change in position 461 did not significantly alter the accumulation level of the virus in protoplasts, deletion of amino acid 461 completely abolishes the functionality of 1a protein.

\section{DISCUSSION}

In our experiments, amino acid 461 of the 1a protein has been shown to play a central role in determining different aspects of the infection. Apart from the obvious influence on symptom manifestation on several Nicotiana spp., the absence of this amino acid ceased viral replication. Such single amino acid changes in viral proteins have been reported to be able to act as necrotic or avirulence determinants in various other viruses. There are examples where nonstructural viral proteins induce necrosis or HR (Jenner et al. 2003; Kim and Palukaitis 1997, Scholtof et al. 1935); however, in many cases it involves the CP (Berzalherranz et al. 1995; Cruz and Baulcombe 1993; Suzuki et al. 1995; Takahashi et al. 2000).

Involvement of CMV RNA1 in symptom determination is rather unusual, but not limited to Ns-CMV. Fny-CMV and Sny-CMV both infect zucchini squash cultivars with different kinetics and symptom severity, both of which have been associated with RNA1 (Gal-On et al. 1994; Roossinck and Palukaitis 1990). In accordance with our observations, the phenotypic difference of infection was not due to differential replication of Fny-CMV and Sny-CMV (Gal-On et al. 1994).

For interpretation of the function of amino acid 461 in triggering the host necrotic response, the gene-for-gene concept provides a good basis. The avirulence factor of the Ns-CMV is clearly the 1a protein: by using reassortant viruses, we were able to localize the necrotic determinant solely to RNA1. According to the gene-for-gene concept, we assume that the introduction of a cysteine at position 461 alters the conformation of the 1a protein or the accessibility or electrostatic pattern of a surface determinant in such a way that 1a protein becomes a ligand of a putative cellular receptor responsible for triggering the molecular cascade resulting in tissue necrosis. Conformational and functional information on the CMV 1a protein mainly derives from data gained by the detailed analysis of the closely related Brome mosaic virus (BMV). Despite low (55\%) similarity at the amino acid level, CMV and BMV 1a proteins share identical structural features (O'Reilly et al. 1998). Secondary structure prediction placed amino acid 461 in the middle of an $\alpha$-helix with $>80 \%$ confidence. Three amino acid insertions in this $\alpha$-helix rendered the BMV 1a protein nonfunctional by disrupting the structure of the globular C-terminal helicase domain, which also can be found in the CMV 1a protein (O'Reilly et al. 1995). This reports suggests that a mutation in the $\alpha$-helix involving amino acid 461 may have a global (or even deleterious) effect on protein folding. We presume that the 1a protein completely lost its functionality in our experiments due to the $\Delta 461$ deletion; however, the R461C mutation had less impact on the conformation or charge distribution. Nevertheless, this amino acid change might have made the protein capable of triggering a necrotic response. The presence of the cysteine instead of the canonical arginine in position 461 also raises the possibility of alternative disulphide bond formation. Such disulphide bonds can fundamentally change the structure of the 1a protein.

As mentioned above, in addition to direct conformational change of the 1a protein, surface exposure of otherwise hidden domains also can lead to necrosis induction. Like all known RNA viruses, CMV replicates in close association with intracellular membranes (Cillo et al. 2002). In the case of the BMV, this interaction is predominantly mediated by amino acids 367 to 480 of the 1a protein, which corresponds to the 397- to 496amino acid (aa) section of the CMV 1a protein (den Boon et al. 2001). Interestingly, this region of the 1a protein largely overlaps with the particularly important structural $\alpha$-helix described by O'Reilly and associates (1998), which implies a function in both conformation stabilization and membrane association. Based on these considerations, mutations in the 397to 496-aa region of the CMV 1a protein also may lead to necrosis induction by weakening its membrane affinity and in this way exposing normally blocked surfaces of the molecule to the interacting host factor or factors.

Although our results showed the crucial importance of position 461 in the 1a protein in host response determination, experiments with viruses carrying the R461C-mutant Trk7 1a protein may shed light on other factors required for the R461C mutation-triggered necrosis induction. These additional factors are likely subgroup I-specific intramolecular interactions, which are not present in the mutated subgroup II 1a protein. The lack of such interactions could explain why the R461C mutation is ineffective in the case of the Trk7 strain.

\section{MATERIALS AND METHODS}

\section{Viruses and characterization of their pathology.}

Rs-CMV, a subgroup I strain, was isolated from $R$. sativus and kindly provided by Pál Salamon (P. Salamon, unpublished data). Host range and pathology of the Ns-CMV, a derivative of Fulton's necrotic strain (Fulton 1953), has been characterized previously (Salamon et al. 1998). Test plants were kept in environmentally controlled growth chambers at cycle of $14 \mathrm{~h}$ of light $\left(23^{\circ} \mathrm{C}\right)$ and $10 \mathrm{~h}$ of dark $\left(18^{\circ} \mathrm{C}\right)$. The plants were mechanically inoculated at the fourth-leaf stage ( $N$. glutinosa and N. tabacum cv. Xanthi-nc) or at 3 weeks old ( $N$. clevelandii) with in vitro RNA transcripts from cDNA clones. Symptoms were observed at 10 dpi. For the demonstration of the symptoms of the Ns and Rs strains (Fig. 1 ), virions at a concentration of $10 \mu \mathrm{g} / \mathrm{ml}$ were used as inoculum. Viruses were propagated on $N$. benthamiana and purified (Lot et al. 1972) prior to inoculation. In each case, the indicated data represent the result of at least three independent experiments.

\section{Generation and sequencing of the cDNA clones of viral genomes.}

First-strand cDNAs were synthesized using M-MuLV reverse transcriptase (MBI Fermentas, Vilnius, Lithuania), applying the protocol provided by the manufacturer. Oligonucleotide (5'gcggatcctggtctccttt $\left.3^{\prime}\right)$ complementary to the $3^{\prime}$ conserved sequence of the viral RNAs, containing a flanking BamHI recognition site (underlined), was used to initiate the synthesis. For subsequent polymerase chain reaction (PCR) amplification of cDNA1 and cDNA2, the same $3^{\prime}$ primer and a $5^{\prime}$ primer (5'gggggcctaatacgactcactatagtttatttacaagagcg $3^{\prime}$ ), containing a flanking ApaI recognition site (underlined) and a T7 RNA polymerase promoter sequence (italics), were used. For the amplification of the cDNA3, the $5^{\prime}$ oligonucleotide $\left(5^{\prime}\right.$ ggctgcagta atacgactcactatagtaatcttaccac $3^{\prime}$ ) contained a PstI recognition site. After the PCR, the product was digested with ApaI/BamHI or PstI/BamHI, and ligated into similarly treated pBluescriptII $\mathrm{KS}+$ (Stratagene, La Jolla, CA, U.S.A.) vector, resulting in the $\mathrm{pN} 1, \mathrm{pN} 2$, and $\mathrm{pN} 3$, and $\mathrm{pR} 1, \mathrm{pR} 2$, and $\mathrm{pR} 3$ clones, respectively. After assuring the infectivity of RNA 1-2-3 sets synthesized in vitro from the appropriate cDNAs, nucleotide sequences of the cDNA clones were determined using automated fluorescent dideoxy-sequencing. cDNA clones of the Trk7-CMV (pTrk1, pTrk2, and pTrk3) have been described previously (Salánki et al. 1997; Szilassy et al. 1999b). 
Table 2. Oligonucleotide primers used for site-directed mutagenesis of cDNA1s ${ }^{\mathrm{a}}$

\begin{tabular}{|c|c|c|c|}
\hline Mutant & Forward oligonucleotide primer & Reverse oligonucleotide primer & Endonuclease recognition site \\
\hline prL456F & tccggccgctgcgtg & ttcggccgagtAAAcgcg & XmaIII \\
\hline prR461C & tccggccgctgTGTgtg & ttcggccgagtcaacgcg & XmaIII \\
\hline prV462Q & tccggecgctgcgtCAGttttc & ttcggccgagtcaacgcg & XmaIII \\
\hline prV467A & gtctGCAgttcacgcactattcce & ggcTGCagaggagaaaaacacac & Pst $\mathrm{I}$ \\
\hline prH469R & cCGAgctctattcccgactttg & gggagcTCGaacaacactggag & SacI \\
\hline pnC461R & ggcttaAGGcagttttctctag & agCTtaagggacgagtaaatgc & AflII \\
\hline $\mathrm{pn} \Delta 461$ & tacggccgctg.cagtttttc & ttcggccgagtaaatgctgc & XmaIII \\
\hline ptR461C & tccggecgttcTGTgtttc & ttcggccgagacatagacgc & XmaIII \\
\hline
\end{tabular}

${ }^{a}$ Oligonucleotides are written in $5^{\prime}$ to $3^{\prime}$ direction. Embedded endonuclease recognition sites are underlined. Mutagenized codons are capitalized.

\section{Infectious transcripts and generation}

of chimeric and mutant RNA1 constructs.

Infectious transcripts from full-length cDNA clones were synthesized according to the previously described protocol (Szilassy et al. 1999b).

The chimeric RNA1s were constructed by using the common restriction enzyme recognition sites indicated in Figure 2A. The cloning steps were carried out according to standard laboratory procedures (Sambrook et al. 1989). Prior to PCRbased site-directed mutagenesis of the $\mathrm{pN} 1, \mathrm{pR} 1$, and pTrk1 clones, the XmaIII site in the multicloning region was removed by XmaIII linearization, T4 DNA polymerase digestion, and recircularization. Letters $n, r$, and thave been assigned to the name of the mutant clones based on $\mathrm{pN} 1 \Delta \mathrm{Xma}$, pR1 $1 \Delta \mathrm{Xma}$, and pTrk1 $\Delta \mathrm{Xma}$ templates, respectively. Oligonucleotide primers intended to insert point mutations were designed with the SilMut software package (available online from IUBio Software Archive). All oligonucleotides contained a restriction enzyme site to facilitate the circularization of the PCR product (Table 2). Templates were amplified with $P f u$ polymerase to minimize the chance of nonintentionally introduced mutations. PCR products were circularized after cutting with the endonucleases whose recognition sites have been included in the primers as silent mutations. Nucleotide sequences of the mutant cDNA1 clones were verified with automated dideoxysequencing. The M-fold web site (Zuker 2003) was used for the prediction of secondary RNA structures. For each calculation, the offered default parameters were accepted.

\section{Preparation and transfection of protoplasts.}

Protoplasts were isolated from fully expanded leaves of $N$. clevelandii plants and purified in $\mathrm{K} 3$ medium containing $0.4 \mathrm{M}$ sucrose as described by Nagy and Maliga (1976). Protoplast transfection with $2 \mu \mathrm{g}$ of purified viral RNA or in vitro RNA transcripts was carried out as described by Kroner and Ahlquist (1992). Briefly, $100 \mu \mathrm{l}$ of a protoplast suspension of $2.5 \times 10^{6}$ protoplasts $/ \mathrm{ml}$ was treated for $5 \mathrm{~s}$ with $200 \mu \mathrm{l}$ of $40 \%$ polyethylene glycol (molecular weight approximately 1500) and $3 \mathrm{mM}$ $\mathrm{CaCl}_{2}$ containing $2 \mu \mathrm{g}$ of RNA. After dilution and washing, protoplasts were incubated in $1 \mathrm{ml}$ of $\mathrm{K} 3$ and $0.4 \mathrm{M}$ glucose for 24 $\mathrm{h}$ in a growth chamber at a cycle of $14 \mathrm{~h}$ of light $\left(23^{\circ} \mathrm{C}\right)$ and 10 $\mathrm{h}$ of dark $\left(18^{\circ} \mathrm{C}\right)$. Nucleotide sequences of the purified viral RNAs were verified by reverse-transcriptase PCR followed by automated fluorescent dideoxy-sequencing prior to transfection. Protoplasts were centrifuged at $65 \times g$ for $5 \mathrm{~min}$. Supernatant was discarded, and the pellet was processed using the extraction solution and protocol described by White and Kaper (1989). Approximately $5 \mu \mathrm{g}$ of total nucleic was denatured with formaldehyde and formamide, electrophoresed in formaldehyde-containing agarose gel, and blotted onto nylon membrane (Sambrook et al. 1989). After crosslinking, the membrane was hybridized with ${ }^{32} \mathrm{P}$-labeled, random-primed probe synthesized from the HindIII-BamHI fragment (nucleotides 1,563 to 2,216) of the pN3 clone. Radioactivity was visualized using a storage phosphor screen and matching scanner (Molecular Dynamics,
Sunnyvale, CA, U.S.A.). The protoplast analyses were carried out in triplicates.

\section{ACKNOWLEDGMENTS}

The authors are grateful to P. Salamon for kindly providing the NsCMV and Rs-CMV isolates. The skillful technical assistance of J. Novák Nádudvari is highly appreciated. We wish to thank B. Kupcsulik (Budapest University of Technology and Economics) for his useful comments on the manuscript. K. Salánki was supported by the Bolyai János fellowship of the Hungarian Academy of Sciences. This work was funded in part by the OTKA-TS044877 Science School grant.

\section{LITERATURE CITED}

Berzalherranz, A., Delacruz, A., Tenllado, F., Diazruiz, J. R., Lopez, L., Sanz, A. I., Vaquero, C., Serra, M. T., and Garcialuque, I. 1995. The capsicum L(3) gene-mediated resistance against the tobamoviruses is elicited by the coat protein. Virology 209:498-505.

Brigneti, G., Voinnet, O., Li, W. X., Ji, L. H., Ding, S. W., and Baulcombe, D. C. 1998. Viral pathogenicity determinants are suppressors of transgene silencing in Nicotiana benthamiana. EMBO (Eur. Mol. Biol. Organ.) J. 17:6739-6746

Canto, T., Prior D. A. M., Hellwald, K.-H., Oparka, K. J., and Palukaitis, P. 1997. Characterization of cucumber mosaic virus. IV. Movement protein and coat protein are both essential for cell-to-cell movement of cucumber mosaic virus. Virology 237:237-248.

Cillo, F., Roberts, I. M., and Palukaitis, P. 2002. In situ localization and tissue distribution of the replication-associated proteins of Cucumber mosaic virus in tobacco and cucumber. J. Virol. 76:10654-10664.

Cruz, S. S., and Baulcombe, D. C. 1993. Molecular analysis of Potato virus $\mathrm{X}$ isolates in relation to the potato hypersensitivity gene Nx. Mol. Plant-Microbe Interact. 6:707-714.

den Boon, J. A., Chen, J., and Ahlquist, P. 2001. Identification of sequences in Brome mosaic virus replicase protein 1a that mediate association with endoplasmic reticulum membranes. J. Virol. 75:12370-12381.

Ding, S. W., Li, W. X., and Symons, R. H. 1995. A novel naturally occurring hybrid gene encoded by a plant RNA virus facilitates long distance virus movement. EMBO (Eur. Mol. Biol. Organ.) J. 14:5762-5772.

Fulton, R. W. 1953. Resistance in tobacco to cucumber mosaic virus infection. (Abstr.) Phytopathology 43:472.

Gal-On, A., Kaplan, I., Roossinck, M. J., and Palukaitis P. 1994. The kinetics of infection of zucchini squash by cucumber mosaic virus indicate a function for RNA1 in virus movement. Virology 205:280-289.

Goldbach, R., Bucher, E., and Prins, M. 2003. Resistance mechanisms to plant viruses: an overview. Virus Res. 92:207-212.

Gorbalenya, A. E., Koonin, E. V., Donchenko A. P., and Blinov, V. M. 1988. A novel superfamily of nucleotide triphosphate-binding motif containing proteins which are probably involved in DNA and RNA replication and recombination. FEBS (Fed. Eur. Biochem. Soc.) Lett. 235:16-24.

Habili, N., and Symons, R. H. 1989. Evolutionary relationship between luteoviruses and other RNA plant viruses based on sequence motifs in their putative RNA polymerases and nucleic acid helicases. Nucleic Acids Res. 17:9543-9555.

Haseloff, J., Godet, P., Zimmern, D., Ahlquist P., Dasgupta, R., and Kaesberg, P. 1984. Striking similarities in amino acid sequence among nonstructural proteins encoded by RNA viruses that have dissimilar genomic organization. Proc. Natl. Acad. Sci. U.S.A. 81:4358-4362.

Hayes, R. J., and Buck, K. W. 1990. Complete replication of a eukaryotic virus RNA in vitro by a purified RNA-dependent RNA polymerase. Cell 63:363-368.

Heath, M. C. 2000. Hypersensitive response-related cell death. Plant Mol. Biol. 44:312-334. 
Hulbert, S. H., Webb, C. A., Smith, S. M., and Sun, Q. 2001. Resistance gene complexes: Evolution and utilization. Annu. Rev. Phytopathol. 39:285-312.

Hutcheson, S. W. 1998. Current concepts of active defense in plants. Annu. Rev. Phytopathol. 36:59-128.

Jenner, C. E., Wang, X. W., Tomimura, K., Ohshima, K., Ponz, F., and Walsh, J. A. 2003. The dual role of the potyvirus P3 protein of turnip mosaic virus as a symptom and avirulence determinant in brassicas. Mol. Plant-Microbe Interact. 16:777-784.

Kim, C. H., and Palukaitis, P. 1997. The plant defense response to cucumber mosaic virus in cowpea is elicited by the viral polymerase gene and affects virus accumulation in single cells. EMBO (Eur. Mol. Biol. Organ.) J. 16:4060-4068.

Kroner, P., and Ahlquist, P. 1992. RNA-based viruses. Pages 23-24 in: Molecular Plant Pathology. A Practical Approach. Vol. I. IRL Press, Oxford.

Lakshman, D. K., and Gonsalves, D. 1985. Genetic analyses of two largelesion isolates of cucumber mosaic virus. Phytopathology 75:758-762.

Li, Q. B., Ryu, K. H, and Palukaitis, P. 2001. Cucumber mosaic virusplant interactions: Identification of 3 a protein sequences affecting infectivity, cell-to-cell movement, and long-distance movement. Mol. Plant-Microbe Interact. 14:378-385.

Lot, H. W., Marrou, J., Quiot, J. B., and Esvan, C. 1972. Contribution à l'étude du virus de la mosaique du concombre (CMV). I. Méthode de purification rapide du virus. Ann. Phytopathol. 4:25-38.

Nagy, J. I., and Maliga, P. 1976. Callus induction and plant regeneration from mesophyll protoplasts of Nicotiana sylvestris. Z. Pflanzenphysiol. 78:453-455

O'Reilly, E. K., Tang, N., Ahlquist, P., and Kao, C. C. 1995. Biochemical and genetic analyses of the interaction between helicase-like and polymerase-like proteins of the Brome mosaic virus. Virology 214:59-71.

O'Reilly, E. K., Whang, Z., French, R., and Kao, C. C. 1998. Interactions between the structural domains of the RNA replication proteins of plant-infecting RNA viruses. J. Virol. 72:7160-7169.

Palukaitis, P., Roossinck, M. J., Dietzgen, R. G., and Francki R. I. B. 1992. Cucumber mosaic virus. Adv. Virus Res. 41:281-348.

Roossinck, M. J., and Palukaitis, P. 1990. Rapid induction and severity of symptoms in zucchini squash (Cucurbita pepo) map to RNA-1 of Cucumber mosaic virus. Mol. Plant-Microbe Interact. 3:188-192.

Roossinck, M. J., Zhang, L., and Hellwald, H. L. 1999. Rearrangements in the $5^{\prime}$ nontranslated region and phylogenetic analyses of cucumber mo- saic virus RNA3 indicate radial evolution of three subgroups. J. Virol. 71:3597-3602.

Salamon, P., Salánki, K., Szilassy, D., and Balázs, E. 1998. Characterization of a necrotic strain of cucumber mosaic virus (CMV-N). Növényvédelem 34:583-591.

Salánki, K., Carrère, I., Jacquemond, M., Balázs, E., and Tepfer, M. 1997. Biological properties of pseudorecombinant and recombinant strains created with cucumber mosaic virus and tomato aspermy virus. J. Virol. 71:3597-3602.

Sambrook, J., Fritsch, E. F., and Maniatis, T. A. 1989. Molecular Cloning: A Laboratory Manual. 2nd ed. Cold Spring Harbor Laboratory Press, Cold Spring Harbor, NY, U.S.A.

Scholtof, H. B., Scholthof, K. B., Kikkert, M., and Jackson, A. O. 1995. Tomato bushy stunt virus spread is regulated by two nested genes that function in cell-to-cell movement and host-dependent systemic invasion. Virology213:425-438.

Shi, B. J., Palukaitis, P., and Symons, R. H. 2002. Differential virulence by strains of Cucumber mosaic virus is mediated by the $2 b$ gene. Mol Plant-Microbe Interact. 15:947-955.

Suzuki, M., Kuwata, S., Masuta, C., and Takanami Y. 1995. Point mutations in the coat protein of Cucumber mosaic virus affect symptom expression and virion accumulation in tobacco. J. Gen. Virol. 76:17911799.

Szilassy, D., Salánki, K., and Balázs, E. 1999a. Stunting induced by cucumber mosaic cucumovirus-infected Nicotiana glutinosa is determined by a single amino acid residue in the coat protein. Mol. PlantMicrobe Interact. 12:1105-1113.

Szilassy, D., Salánki K., and Balázs, E. 1999b. Molecular evidence for the existence of two distinct subgroups in cucumber mosaic cucumovirus. Virus Genes 18:221-227.

Szittya, G., and Burgyán J. 2001. Cymbidium ringspot tombusvirus coat protein coding sequence act as an avirulent RNA. J. Virol. 75:24112420

Takahashi, H., Sugiyama, M., Sukamto, Karasawa, A., Hase, E., and Ehara, Y. 2000. A variant of Cucumber mosaic virus is restricted to local lesions in inoculated tobacco leaves with a hypersensitive response. J. Gen. Plant Pathol. 66:335-344.

White, J. L., and Kaper, J. M. 1989. A simple method for detection of viral satellite RNAs in small tissue samples. J. Virol. Methods 23:83-94.

Zuker, M. 2003. Mfold web server for nucleic acid folding and hybridization prediction. Nucleic Acids Res. 31:3406-3415. 